\title{
Peran Lagu Perjuangan dan Pendidikan Kesadaran Nasionalisme di Indonesia
}

\author{
Wisnu Mintargo \\ Dosen Fakultas Seni Pertunjukan, Institut Seni Indonesia Surakarta.
}

\begin{abstract}
This paper discusses the role of national battle songs as well as educational songs in raising the awareness of nationalism in Indonesian society. The study of song function in Indonesian society is done through sociological approach of music by applying contextual and constructive method of musicological analysis. This study concludes that Indonesian national songs are the musical expression of the former nation' warriors, their melody are simple, and using Indonesian text. Sociologically the songs were written due to the pressure of the colonizers.
\end{abstract}

Keywords: battle songs; natinalism; music

\begin{abstract}
Abstrak
Paper ini membahas peran lagu-lagu perjuangan dan lagu-lagu pendidikan dalam menumbuhkan kesadaran nasionalisme pada masyarakat Indonesia. Kajian fungsi lagu pada masyarakat Indonesia dilakukan melalui pendekatan sosiologi musik dengan menerapkan analisis kontekstual dan konstruktif musikologis. Kajian ini menyimoulkjan bahwa lagu-lagu kebangsaan Indonesia adalah ekspresi para pejuang bangsa yang seara musikologis melodinya dibuat sederhana, menggunakan teks berbahasa Indonesia. Secara sosiologis lagu-lagu tersebut tercipta akibat adanya tekanan dari bangsa penjajah
\end{abstract}

Kata kunci: Lagu-lagu perjuangan; nasionalisme; musik

\section{Pengantar}

Berkembangnya nasionalisme modern di Eropa yang dipelopori oleh kalangan ahli ilmu pengetahuan, di Indonesia lahir kebangkitan nasionalisme yang dipandang sebagai awal tumbuh dan berkembangnya sejarah yang pertama kali dipelopori oleh tokoh nasional seperti Dr. Sutomo dan Dr. Wahidin Sudirohusodo. Nasionalisme bangkit ditandai lahirnya semangat nasional melalui organisasi Boedi Oetomo yang didirikan pada tanggal 20 Mei 1908 dengan tujuan "Mencerdaskan Bangsa", yang berdasarkan kesadaran, tekad dan upaya untuk memajukan bangsa atas dasar falsafah dan wawasan yaitu bersumber pada kepribadian Nusantara, didukung para cendekiawan yang berbasis pada pendidikan nasional untuk melawan bangsa penjajah (H. Kaelan, 2001: 705).

Nasionalisme merupakan kesadaran bersama yang dapat memeprsatukan sukusuku bangsa yang hidup di Nusantara. Nasionalisme di Indonesia lahir bersamaan dengan tumbuhnya keinginan seluruh rakyat Indonesia membentuk negara kesatuan (B. Setiawan, 1998: 33). Dalam perjalanan sejarah di Indonesia bangsa Belanda pernah mengajarkan instrumen musik Barat kepada Abdi Dalem di Kasultanan Kraton Yogyakarta dan Kraton Surakarta tujuannya ialah agar dapat memainkan lagu kebangsaan "Wilhelmus" saat upacara kunjungan tamu resmi para pejabat dari negeri Belanda. 
Di sisi lain perlakuan yang istimewa terhadap lagu kebangsaan "Indonesia Raya" serta diakuinya bahasa Melayu sebagai bahasa Indonesia memicu timbulnya peluang bagi kelompok cendekiawan Jawa yang ingin menguasai lagu kebangsaan dengan alternatif musik ritual yang khas dapat mewakili puncak kebudayaan nasional melalui instrumen gamelan. Usaha tersebut dilakukan dengan mencoba untuk mengerahkan para empu gamelan di tahun 1930-an untuk memodernisir gamelan baik dari segi praktek maupun teori. Perubahan-perubahan dalam notasi musik diantaranya pernah ditulis dalam buku kecil Mr. Muhammad Yamin, bahwa usaha-usaha untuk memainkan lagu kebangsaan "Indonesia Raya" terbukti mengalami kegagalan, oleh karena secara teknis lagu tersebut memakai sistem tangga nada diatonis, sedang untuk instrumen gamelan memakai sistem tangga nada pentatonik.

Masa perjuangan Indonesia melawan kolonialisme perkembangan musik diatonis berubah menjadi fenomena politik, disebabkan perbedaan pandangan tentang musik nasional. Perkembangan msuik diatonis sebagai sarana pendidikan nasionalisme mengalir seiring munculnya generasi penerus setelah W.R. Supratman dan M. Syafei pendiri sekolah I.N.S. Kayutanam di Sumatera Barat, yaitu kelompok pemusik asal daerah Tapanuli dengan latar belakang pengetahuan musik gereja misionaris Jerman yang cukup handal. Para pemusik terkenal adalah Cornel Simandjuntak (Komponis), Amir Pasaribu (Kompnis, Kritikus), J.A. Dungga (Kritikus), L. Manik (Komponis, Kritikus), Binsar Sitompul (Kompnis), dan W. Lumban Tobing (Etnomusikolog) (Franki, 1994: 7). Di Jawa dikenal Ismail Marzuki (Komponis), Kusbini (Komponis), Bintang Sudibyo (Komponis), R.A. Sudjasmin (Komponis, Pendidik). Pemusik tidak hanya beranggapan bahwa budaya musik nasional eksotisme tidak boleh dibangun diatas budaya musik Jawa, tetapi harus mengikuti pola musik diatonis yang secara umum lebih mudah diterima oleh seluruh masyarakat dengan berbagai kebinekaannya.

Usaha seperti ini sebanarnya telah dirintis jauh sebelum itu oleh para pemuda di tahun 1920-an menjelang sumpah pemuda, mengenai peranan musik diatonis yang dapat mewakili berbagai suku di Indonesia. Diantaranya dihimpun oleh organisasi kepemudaan antara lain Paguyuban Pasundan, Jong Java, Jong Sumatera Bond, Jong Minahasa, Jong Ambon, Jong Celedas, Jong Timorsch Verbond, Kaum Betawi, Sekar Rukun, Islamieten Bond. Perkumpulan itu adalah cikal bakal perjuangan kedaerahan setelah tahun 1926 meningkat kearah persatuan pemuda semakin kuat. Sejak itu tumbuh dan berkembangnya nasionalisme di Indonesia tidak haya didasarkan pada persamaan primordialistik, akan tetapi sudah bersifat terbuka. Diilhami oleh cita-cita kebangkitan nasional dari tahun 1908, pada tanggal 28 Oktober 1928 pemuda Indonesia mengikrarkan Sumpah Pemuda, yaitu satu nusa, satu bangsa, dan satu bahasa. Bahasa Melayu yang diakui sebagai bahasa nasional, merupakan suatu kekalahan bagi bangsa Belanda, sebagai simbol ikrar, teks Sumpah Pemuda serta lagu kebangsaan "Indonesia Raya" menggunakan bahasa Indonesia dan berlakunya musik diatonis. Akhirnya guna menetralisir keanekaragaman pemuda Indonesia peranan musik nasional tidak lagi berpihak kepada etnis Jawa atau salah satu budaya etnis di Nusantara, melainkan harus bersifat universal seperti dalam kedudukan musik diatonis. Oleh karena itu sistem tangga nada diatonis dan pelog yang mendasari lagu-lagu instrumen gamelan perlu dihindari (R.M. Soedarsono, 1998: 39).

\section{Pembahasan}

\section{Fungsi Lagu Perjuangan Indonesia}

Lagu perjuangan Indonesia disebut juga sebagai musik fungsional yaitu musik yang diciptakan untuk tujuan nasional. Salah satu contoh dimaksudkan musik fungsional 
dalam sejarah musik, seperti musik digunakan mengiringi peribadatan agama (ritual), musik untuk mengiringi tari sebagai sarana hiburan. Fungsi primer dari lagu-lagu perjuangan adalah sebagai sarana upacara, dimana kedudukan pemain serta peserta didalam seni pertunjukkan harus terlibat, hingga seni pertunjukkan jenis ini bisa disebut Art of participation. Fungsi sekunder lagu-lagu perjuangan digunakan sebagai media agitasi politik dalam membangkitkan semangat perjuangan melawan penjajah, dan keberadaan jenis lagu-lagu ini di Indonesia pada masa perang kemerdekaan jumlahnya cukup banyak (R.M. Soedarsono, 2001: 170171). Sebagai seni pertunjukkan dalam lagulagu perjuangan idiom musik Barat dikemas berdasarkan kemampuan musikologis masyarakat pendukungnya. Unsur teknis bernyanyi tidak begitu penting, diutamakan makna serta isi teks lagu bersifat agitasi disampaikan kepada masyarakat pendukungnya mudah dinyanyikan dan dihayati seluruh masyarakat Indonesia.

Secara umum pengertian lagu perjuangan adalah kemampuan dan daya upaya yang muncul melalui media kesenian di dalam peranannya pada peristiwa sejarah kemerdekaan di Indonesia (Sri Martono, 1953: 668). Upaya ini disebut sebagai sikap patriotis di dalam konteks sejarah sebelum dan sesudah Kemerdekaan R.I. tanggal 17 Agustus 1945, pada masa perang kemerdekaan dan revolusi di Indonesia. Dalam pengertian yang luas sebagai perasaan nasional lagu-lagu perjuangan disebut sebagai lagu wajib yang diajarkan mulai pada tingkat pendidikan dasar, hingga perguruan tinggi dan wajib diketahui seluruh masyarakat Indonesia. Ditegaskan pula menurut peraturan pemerintah berdasarkan Instruksi Menteri Muda Pendidikan Pengajaran dan Kebudayaan No. 1 tanggal 17 Agustus 1959 yang diterbitkan oleh Balai Pustaka tahun 1963, telah ditetapkan 7 (tujuh) buah lagu perjuangan sebagai lagu wajib yaitu: (1) Lagu kebangsaan "Indonesia Raya” ciptaan Wage
Rudolf Supratman. (2) Lagu "Bagimu Negeri” ciptaan Kusbini. (3) Lagu “Maju Tak Gentar" ciptaan Cornel Simanjuntak. (4) Lagu "Halo-halo Bandung" ciptaan Ismail Marzuki. (5) Lagu "Rayuan Pulau Kelapa" ciptaan Ismail Marzuki. (6) Lagu "Berkibarlah Benderaku" ciptaan Bintang Sudibyo. (7) Lagu "Satu Nusa Satu Bangsa" ciptaan L. Manik.

Fakta sejarah dapat dipahami dengan baik, hanya jika terlebih dahulu memahami kondisi yang melatar belakanginya dan dapat menentukan hubungan antara kondisi dan fakta. Hal ini disebabkan setiap masyarakat sebagai unit merasakan pengaruh dan bereaksi terhadap lingkungannya. Teori geografi mengenai interaksi manusia dan alam yang penting disini adalah teori posibilisme, yang menerangkan bahwa alam sekedar menawarkan berbagai kemungkinan untuk dimanfaatkan oleh manusia melalui sikap dan cara berpikirnya (Garraghan, 1957: 339) (Daldjoeni, 1987: 7).

Menurut James C. Dibdin (1962), analisis secara historis karakter suatu bangsa dapat dianalisis melalui sikap serta pemikiran nasionalnya yaitu: (1) Karakter bangsa yang mempunyai sifat pendendam dan kejam dalam peperangan. (2) Karakter bangsa yang mempunyai sifat pemalas dan enggan berusaha. (3) Karakter bangsa yang mempunyai sifat kesatria bila harus berjuang menghadapi tantangan dan penindasan (Rolland, 1962: 525). Sikap patriotisme dan pemikiran nasional pada bagian akhir inilah yang dimiliki oleh bangsa Indonesia dengan berhasil merebut kemerdekaan, tercermin dari motivasi lagu-lagunya yang mampu menggelorakan semangat patriotisme berdasarkan cita-cita kemerdekaan yang sedang diperjuangkan. Sebab sejak meletusnya revolusi tahun 1945, lenyap pula lagu-lagu berbahasa Jepang dan lagu propaganda Asia Timur Raya, dalam kondisi seperti ini terjadi kekosongan bagi dunia pendidikan yang sangat memerlukan pelajaran kesenian. 
Pemerintah Indonesia tidak dapat berbuat banyak, untuk mengimbangi kekosongan setiap sekolah harus mengusahakan sendiri lagu-lagu tersebut, salah satunya adalah memanfaatkan lagu-lagu perjuangan sebagai sarana pendidikan kesadaran nasionalisme dan patriotisme. Selain itu sebagai ujud kecintaan pada tanah air peranan tersebut selain simbol nasional seperti bendera nasional, lagu kebangsaan, cerita kepahlawanan rakyat, dan ornamenornamen lain juga dapat memotivasi warga negara dalam mewujudkan kebersamaan di dalam perjuangan. Untuk itu pendidikan nasionalisme melalui kesenian mulai diajarkan kepada anak-anak sejak dini baik di sekolah, di rumah, dan di lingkungannya, karena dapat menimbulkan rasa memiliki terhdaap nilai-nilai kesintaan pada tanah air, misalnya dengan menampilkan tokoh kepahlawanan lewat media kesenian dapat pula menyalurkan rasa nasionalisme kedalam diri individu sesuai dengan cita-cita bangsa Indonesia yaitu membangkitkan persatuan dan kesatuan. Uraian tersebut di atas secara singkat dapat dijelaskan bahwa nasionalisme memiliki pengaruh besar terhadap musik nasional. Bahasa sebagai alat komunikasi merupakan faktor pemersatu berbagai jenis etnis yang berbeda-beda.

\section{Analisis Konstruktif Lagu Ritual dan Se- mangat Patritisme}

Selanjutnya keberadaan media kesenian seperti fungsi lagu-lagu perjuangan Indonesia di dalam perkembangannya saat ini dapat dikategorikan menjadi 2 bagian sebagai berikut. Fungsi Konstruktif lagu untuk upacara fungsi primer bersifat konstruktif berisi pesan pembangunan sebagai sarana seremonial dalam suatu kegiatan upacara bersifat kenegaraan yaitu lagu kebangsaan "Indonesia Raya" ciptaan W.R. Supratman dan lagu "Bagimu Negeri" ciptaan Kusbini. Lagu-lagu tersebut usianya lebih tua dibandingkan dengan lagu perjuangan lainnya dan secara umum dilaksanakan pada saat tertentu dalam posisi berdiri ditempat sebagai penghormatan terhadap lambang negara dan lagu sumpah bakti kepada nusa dan bangsa diungkapkan dengan rasa khidmat secara mendalam. Lagu-lagu tersebut diciptakan sebelum revolusi bahkan peranannya sangat penting pada masa perang kemerdekaan di Indonasia tahun 1945 - 1949. Selain itu dengan diperdengarkannya lagu adanya tanda bahwa Indonesia masih memiliki harapan untuk bangkit sebagai negara yang merdeka, guna merubah persepsi pada siatuasi keadaan yang pesimis menjadi suatu sikap yang optimis menjadi perbuatan konstruktif (Victor Tuner, 1967: 53). Hal ini dapat dibuktikan pada tanggal 22 Juli 2001 lagu kebangsaan "Indonesia Raya" dan lagu "Bagimu Negeri" berkumandang mengiringi upacara pembukaan serta acara penandatanganan serah terima jabatan Kepala Negara. Dalam sidang Istimewa tampak ketua MPR Amin Rais memberikan mandat kepada Presiden R.I. Megawati Sukarnoputri, disaksikan para wakil rakyat dalam upacara penetapan dan pengangkatan Wakil Presiden menjadi Presidan R.I. di Gedung MPR R.I. Jakarta (Slade, 1997: 170).

Fungsi sekunder bersifat konstruktif, ialah lagu perjuangan sebagai sarana pembangkit semangat solidaritas bangsa cinta tanah air digunakan menghimpun persatuan dan kesatuan melawan penjajahan di Indonesia. Revolusi di Indonesia mendorong perkembangan pesat dan perubahan lagulagu perjuangan Indonesia. Jiwa revolusi menimbulkan kebebasan serta menghilangkan rasa rendah, sebaliknya merubah keberanian. Ritme dan irama mars satu diantaranya lagu hasil kolaborasi propaganda Jepang dimanfaatkan, dan baru pada masa revolusi tahun 1945-1949 dapat dikatakan lain dari pada masa sebelumnya.

Munculnya lagu-lagu perjuangan akhirnya mampu membangkitkan semangat patriotisme di seluruh Nusantara. Jenis lagulagu ini menjadi populer, terutama di Jawa sebagai pusat perjuangan. Masyarakat dapat 
menghafalnya dengan baik mulai dari pelosok kota yang ramai sampai ke daerah pelosok terpencil, melalui karnaval barisan pemuda, barisan tentara pelajar sampai gerakan pelajar, mahasiswa beserta masyarakat berunjuk rasa hingga saat ini masih tetap relevan digunakan lagu-lagu tersebut.

Pada masa perang kemerdekaan penyebaran jenis lagu ini biasanya dilakukan secara lisan seperti mendengar siaran radio, melalui perorangan atau kelompok perkumpulan masyarakat ssuai dengan perkembangan politik pada saat itu. Siaran radio ternyata banyak dimanfaatkan oleh para guru di daerah, mereka mencatat lagu-lagu Indonesia baik melodi maupun syairnya, untuk dilestarikan, kemudian diajarkan kepada murid-murid sekolah swasta yang tidak dikelola oleh pemerintah penjajahan (NonGovernment) sebagai mata pelajaran nilainilai patriotisme (Wisnu, 2001: 66). Kondisi tersebut di atas secara bertahap mengalami kemajuan dan memiliki komunitas tersendiri guna mengimbangi lagu-lagu asing yang populer saat itu. Hal ini membuktikan bahwa bangsa Indonesia berhasil membina persatuan dan kesatuan dengan mengambil alih lagu tersebut untuk tujuan sarana pendidikan kesadaran politik nasional. Terutama pada dekade akhir masa transisi kekuasaan Jepang dan awal penjajahan Belanda yang kembali melancarkan agresinya di Indonesia. Lagu-lagu tersebut kita kenal diantaranya lagu "Maju Tak Gentar" ciptaan Cornel Simanjuntak, "Halo-halo Bandung" ciptaan Ismail Marzuki, "Dari Barat Sampai Ke Timur" ciptaan R. Sunaryo, "Berkibarlah Benderaku” ciptaan Bintang Sudibyo, "Hari Merdeka" ciptaan H. Mutahar, dan lain sebagainya (Wisnu, 2000: 22).

\section{Penutup}

Berdasarkan ketetapan pemerintah tahun 1959, bertujuan untuk diajarkan dalam pendidikan nasional di seluruh tanah air agar diketahui oleh masyarakat Indonesia se- bagai kesadaran wawasan kebangsaan, nasionalisme, patriotisme untuk meningkatkan serta membangkitkan semangat persatuan dan kesatuan negara Republik Indonesia, yaitu sebagai berikut:

Petama, lagu-lagu perjuangan yang diciptakan oleh para komponis Indonesia adalah ekspresi dari perasaan pejuang, melalui ungkapan suara rasa kebangsaan, nasionalisme dan persatuan, yang dapat dibagi menjadi 3 (tiga) tahap: Pertama, melodi diciptakan dengan pola sederhana agar mudah dinyanyikan oleh berbagai lapisan masyarakat Indonesia. Kedua, teks syair menggunakan bahasa Indonesia, agar dipahami oleh seluruh masyarakat Indonesia dengan berbagai kebinekaannya. Ketiga, munculnya lagu-lagu perjuangan Indonesia adalah akibat adanya tekanan dari kaum penjajah pada masa perjuangan dan perang kemerdekaan di Indonesia.

Kedua, ada tahun 1945 Soekarno memerintahkan para komponis Indonesia untuk menyelenggarakan upacara aubade pada hari besar nasional dengan memanfaatkan lagu-lagu perjuangan Indonesia sesuai dengan fungsinya. Untuk memaknai hasil perjuangan bangsa, lagu-lagu tersebut ditetapkan pemeerintah sebagai lagu nasional melalui Surat Keputusan Menteri Muda Pendidikan Pengajaran dan Kebudayaan No. 1 tanggal 17 Agustus 1959, diterbitkan oleh Balai Pustaka pada tahun 1963. Anjuran tersebut sampai saat ini masih tetap dilaksanakan oleh pemerintah dan masyarakat serta dunia pendidikan untuk tetap dilestarikan dan dipakai pada upacara kenegaraan dan puncak hari besar nasional.

\section{Referensi}

Daldjonie, N. Geografi Kesejarahan. Bandung: Alumni, 1987

Garraghan, S.J.; Gilbert, J.A. 1957. Guide to Historical Method. New York: Fordham University of Chicago Press. 
Hall, D.G.E. 1988. Sejarah Asia Tenggara, Terj. I.P. Soewarso. Surabaya: Usaha Nasional,

Kaelan, H. 2000. Pendidikan Pancasila, Yogyakarta: Paradigma,

Mack, Dieter. 1995.Sejarah Musik Jilid 4. Yogyakarta: Pusat Musik Liturgi.

Martono, Sri. 1953. Kehidupan Seni Suara Tahun 1945 - 1952. Yogyakarta: Kementerian Penerangan Republik Indonesia.

Mintargo, Wisnu. 2001 “Fungsi Lagu Perjuangan Indonesia dalam Konteks Kemerdekaan Tahun 19451949". Tesis S-2 Program Studi Pengkajian Seni Pertunjukkan dan Seni Rupa, Yogyakarta: Universitas Gadjah Mada.

Mintargo, Wisnu. 2000. “Lagu Perjuangan Sebagai Media Propaganda", dalam Jurnal Palanta Seni Budaya, No. 6, 2000.
Rolland, Romain, ed. 1962. The International Library of Music for Home and Music Literatur 2. New York: University Society.

Setiawan, B., ed. 1990. Ensiklopedi Nasional Indonesia, Jakarta: Cipta Pustaka.

Slade, Carole. 1997. Form \& Style Tenth Edition. New York: Hougton Mifflin Company,

Soedarsono, R.M. 2001. Metodologi Seni Pertunjukkan dan Seni Rupa. Bandung: Masyarakat Seni Pertunjukan Indonesia.

Soedarsono, R.M. 1998. Seni Pertunjukkan di Era Globalisasi. Jakarta: Direktorat Jenderal Pendidikan Tinggi, Departemen Pendidikan Tinggi, Departemen Pendidikan dan Kebudayaan,

Turner, Victor. 1967. The Forest of Symbols Aspects Ndembu Ritual. Itacha and London: Cornell University, 